\title{
Concussion Risk from Helmeted Sports; A Re-examination of Data and Methods
}

\section{Michael D Freeman*}

Maastricht University, Maastricht, Netherlands

\begin{abstract}
Prior authors have attempted to quantify concussion risk in the general population based on analysis of head impact data gathered from studies of helmeted football players. In the present study potential sources of bias and methodological error in prior concussion risk studies is discussed, including the use of multiple impacts to a single player as independent events, and the failure to describe statistical scatter among the data. A re-analysis of the data is presented in which the highest single impact sustained by each player was matched to concussion presence or absence, resulting in a series of concussion risk curves based on peak acceleration, head injury criterion (HIC), and angular acceleration, with associated $95 \%$ confidence intervals. These data have limited utility for forensic analysis of concussion risk in the general population.
\end{abstract}

Keywords: Concussion; Sports; Forensic; Head; Risk; Biomechanical; Injury; Spine

\section{Introduction}

There have been more than 40 studies published since 2003 which describe a biomechanical analysis of head impacts and concussion risk among football players. A number of the publications have attempted to use these data to extrapolate concussion risk to the general population. This information, in combination with a reconstruction of a head impact event, is sometimes used in a forensic biomechanical analysis as a post hoc means of determining whether a diagnosed traumatic brain injury was truly caused by an investigated head impact.

There are a number of significant problems with using these data in this fashion. First and foremost is the fact that biomechanically-derived injury risk data are continuous, asymptotic, and roughly bell-shaped, meaning that there are relatively few situations in which an observed injury can be said to be impossible. Second, generally accepted methods of assessing individual causation are based on "counterfactual" reasoning, meaning that even if the risk of an injury after a particular event is exceedingly small, if the risk of the injury in the absence of the event is even smaller, then the most probable cause is the event [1]. All causal analyses must employ a counterfactual approach utilizing a comparison of risks, otherwise the inevitable conclusion of an analysis which only describes the numerator risk of injury from an exposure, regardless of the or detail of the biomechanical methods used, will always conclude that a low risk event was not the cause of an injury. As an illustration of the impropriety of such an approach to injury causation, an analysis of the risk of death in most fatal traffic crashes would indicate that only a small proportion of occupants exposed to even very severe crashes die. Such information would be unhelpful for determining the most likely cause of a death observed after a traffic crash, however. This is not say that biomechanical analysis does not have value in the investigation of the cause of an injury, but that the approach has far greater utility in demonstrating how, rather than whether an injury occurred $[2,3]$.

There are a number of other limitations to the use of experimental or population-specific data like the football player concussion studies for assessing the injury risk of a real world event; primarily, that the average or minimal force required to cause a concussion in a helmeted football player is unlikely to be the same as the average or minimal force at which a non-helmeted non-football player sustains a concussion.
Aside from the fact that the athletes are using protective helmets (and as little as $10 \%$ of the acceleration on the helmet is transmitted to the player's head) [4], they are also self-selected as some of the hardiest and most impact-resistant members of the population. An additional factor to consider, from a biomechanical perspective, is the muscular preparation of the football player for the head impact; the effect of stiffening the spine and torso at the time of impact results in great inertial resistance to the sudden load of the impact, as well as decreased displacement of the head.

Further, prior published risk analyses of these data have used the total number of impacts for the denominator (a value in the thousands per player), versus the total number of concussions as the numerator (a single value per player) [5,6], a methodological error that fails to account for the lack of independence in the data. As an illustration, it is readily apparent that the inferred injury risk of 10 similar impacts to an individual would not be the same as 1 impact to 10 different individuals. Potentially, all of the 10 impacts could be below the injury threshold of the single individual regardless of the number of impacts, but the same impact severity could result in injury of 5 out of 10 of the individuals. The failure to account for the fundamental biological characteristic of individual variability in the previous concussion risk studies violates basic practice in the handling of epidemiologic data.

In the present analysis, a comprehensive literature review of studies of head impacts to helmeted athletes in which linear and angular acceleration and Head Injury Criterion (HIC) was conducted. Risk of concussion versus head impact metric per player was modeled using a logistic regression analysis based on the highest magnitude impact sustained by each player, versus the presence or absence of a concussion.

${ }^{*}$ Corresponding author: Michael D Freeman, Faculty of Health, Medicine, and Life Sciences, Maastricht University, Maastricht, Netherlands, Tel: +31-9712551008; Fax: +31-9712551046; E-mail: forensictrauma@gmail.com

Received April 09, 2018; Accepted April 27, 2018; Published May 04, 2018

Citation: Freeman MD (2018) Concussion Risk from Helmeted Sports; A Reexamination of Data and Methods. J Forensic Biomed 9: 139. doi: 10.4172/20902697.1000139

Copyright: ( 2018 Freeman MD. This is an open-access article distributed under the terms of the Creative Commons Attribution License, which permits unrestricted use, distribution, and reproduction in any medium, provided the original author and source are credited. 
Citation: Freeman MD (2018) Concussion Risk from Helmeted Sports; A Re-examination of Data and Methods. J Forensic Biomed 9: 139. doi: 10.4172/2090-2697.1000139

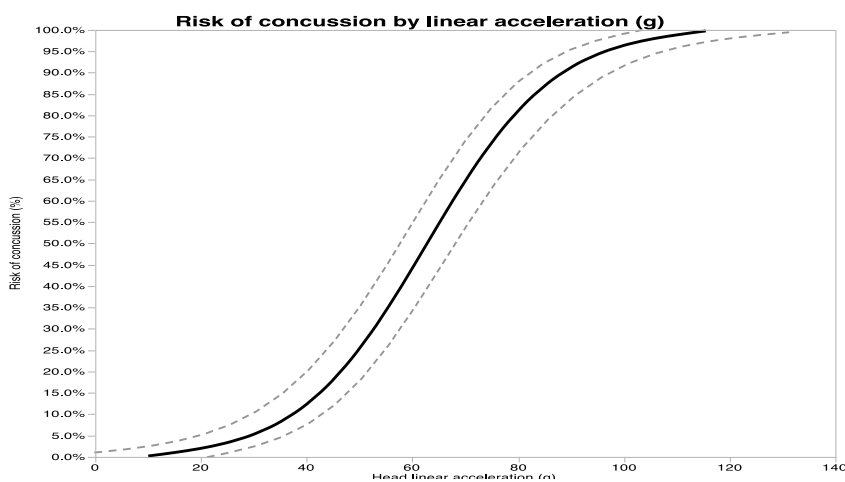

Figure 1: Risk of concussion among 312 non-duplicated helmeted players, by linear acceleration (g). The dashed line indicates the 95\% confidence interval for the risk curve.

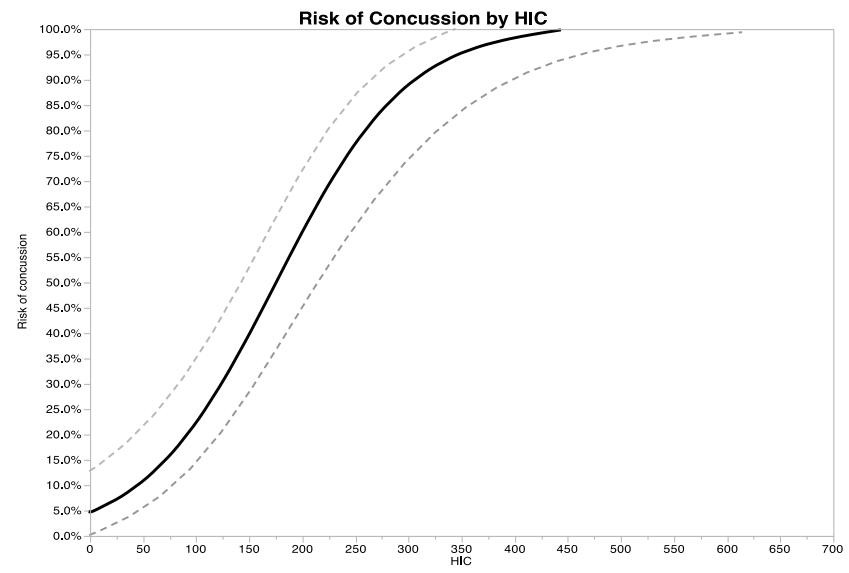

Figure 2: Risk of concussion among 312 non-duplicated helmeted players, by Head Injury Criterion (HIC). The dashed line indicates the $95 \%$ confidence interval for the risk curve.

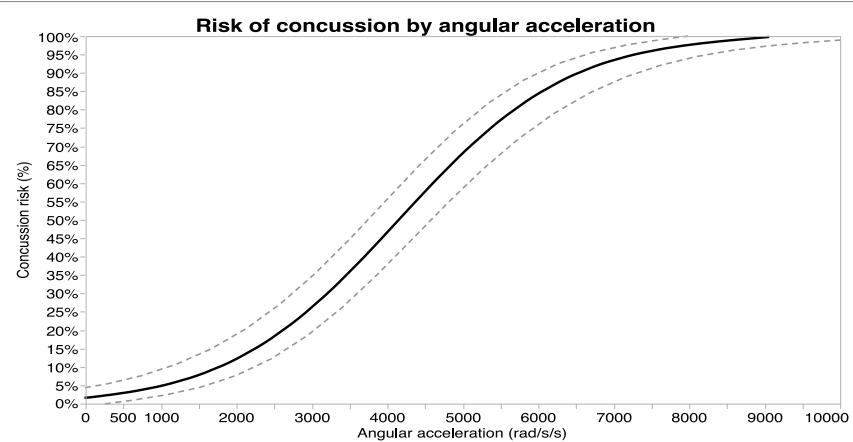

Figure 3: Risk of concussion among 312 non-duplicated helmeted players, by angular acceleration $\left(\mathrm{rad} / \mathrm{s}^{2}\right)$. The dashed line indicates the $95 \%$ confidence interval for the risk curve.

\section{Discussion}

A search of the medical, scientific, and engineering literature revealed 41 publications that described an analysis of head impacts in helmeted athletes. There were 13 of the studies that were not duplicative of a previously described study cohort [5-17]. In these studies there were data available for a total of 2,227 players who had sustained 239,554 head impacts, among whom there were 265 concussions (11.9\%). Among the 2,227 subjects there were 312 non-duplicated subjects for

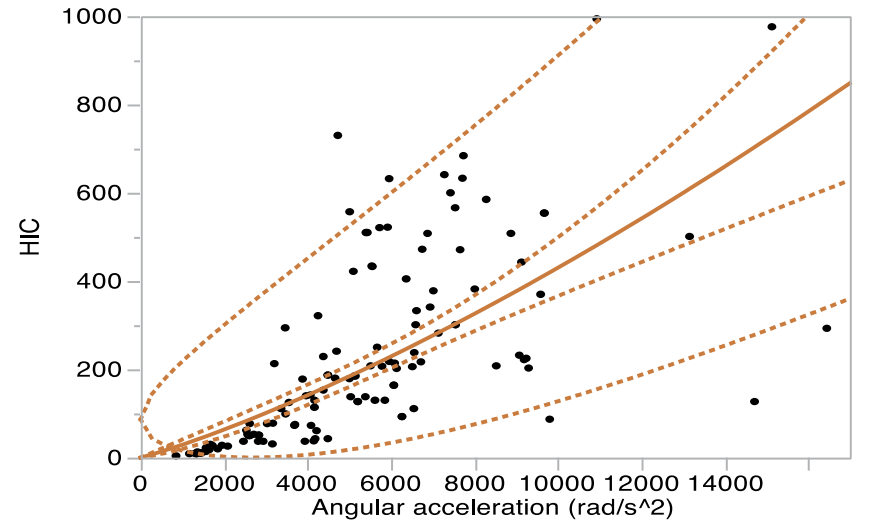

Figure 4: Correlation between angular acceleration and HIC among 312 non-duplicated players, demonstrating the high degree of scatter in the data. The dashed line closest to the solid curvilinear regression line indicates the boundary of $95 \%$ confidence interval, and the outer dashed line indicates the individual predictive interval for the data.

whom there were data available regarding concussion status and linear acceleration, angular acceleration, or HIC.

The average (SD) linear acceleration, HIC, and angular acceleration in the concussed players were $93.2 \mathrm{~g}$ (23.8), 381 (220), and 5,239 $\mathrm{rad} / \mathrm{sec}^{2}$ (2062) respectively. Binomial logistic regression modeling indicated a $5 \%$ risk of concussion at $29.1 \mathrm{~g}$ of linear acceleration, a HIC of 4 , and angular acceleration of 1,009 rad/sec2 (Figures 1-3). Although there was a good correlation between HIC and linear and angular acceleration (Figure 4), at the lower levels of both metrics there was a high degree of scatter.

\section{Conclusion}

Head impact data from helmeted football players provide a basis for understanding the wide range of impacts at which concussions occur in this population, although the accelerations to the helmets are likely substantially greater than to the players' heads. At the lower levels of impact severity the data demonstrate substantial scatter. Injury risk estimates from these data are not extrapolable to the general population of the non-helmeted non-athlete population for the reasons described herein.

Prior authors' use of these data to assess concussion risk based on rates consisting of the number of observed concussions versus the total number of head impacts is methodologically flawed and the resulting risk estimates are unreliable.

\section{References}

1. Freeman MD (2018) A practicable and systematic approach to medicolegal causation. Orthopedics 41: 70-72.

2. Freeman MD, Kohles SS (2011) An evaluation of applied biomechanics as an adjunct to systematic specific causation in forensic medicine. Wiener Medizinische Wochenschrift 161: 458-468.

3. Freeman MD, Kohles SS (2010) Applications and limitations of forensic biomechanics: A Bayesian perspective. J Forensic Leg Med 17: 67-77.

4. Manoogian S, Mcneely D, Goforth M, Brolinson G, Duma S, et al. (2005) Head acceleration is less than 10 percent of helmet acceleration during a football impact. In: ISB XXth Congress - ASB 29th Annual Meeting 159.

5. Rowson S, Duma SM (2013) Brain injury prediction: Assessing the combined probability of concussion using linear and rotational head acceleration. Ann Biomed Eng 41: 873-882.

6. Rowson S, Duma SM, Beckwith JG, Chu JJ, Greenwald RM, et al. (2012) 
Citation: Freeman MD (2018) Concussion Risk from Helmeted Sports; A Re-examination of Data and Methods. J Forensic Biomed 9: 139. doi: 10.4172/2090-2697.1000139

Page 3 of 3

Rotational head kinematics in football impacts: An injury risk function for concussion. Ann Biomed Eng 40: 79-89.

7. Mihalik JP, Bell DR, Marshall SW, Guskiewicz KM (2007) Measurement of head impacts in collegiate football players: an investigation of positional and eventtype differences. Neurosurgery 61: 1229-1235.

8. Guskiewicz KM, Mihalik JP, Shankar V, Marshall SW, Crowell DH, et al. (2007) Measurement of head impacts in collegiate football players: Relationship between head impact biomechanics and acute clinical outcome after concussion. Neurosurgery 61: 1244-1252.

9. Beckwith JG, Greenwald RM, Chu JJ, Crisco JJ, Rowson S, et al. (2013) Head impact exposure sustained by football players on days of diagnosed concussion. Med Sci Sports Exerc 45: 737-746.

10. Broglio SP, Schnebel B, Sosnoff JJ, Shin S, Fend X, et al. (2010) Biomechanical properties of concussions in high school football. Med Sci Sports Exerc 42: 2064-2071.

11. Cobb BR, Urban JE, Davenport EM, Rowson S, Duma SM, et al. (2013) Head impact exposure in youth football: Elementary school ages 9-12 years and the effect of practice structure. Ann Biomed Eng 41: 2463-2473.
12. Daniel RW, Rowson S, Duma SM. (2014) Head acceleration measurements in middle school football. Biomed Sci Instrum 50: 291-296.

13. Schnebel B, Gwin JT, Anderson S, Gatlin R (2007) In vivo study of head impacts in football: a comparison of National Collegiate Athletic Association Division I versus high school impacts. Neurosurgery 60: 490-496.

14. Duhaime AC, Beckwith JG, Maerlender AC, McAllister TW, Crisco JJ, et al. (2012) Spectrum of acute clinical characteristics of diagnosed concussions in college athletes wearing instrumented helmets. J Neurosurg 117: 1092-1099.

15. Duma SM, Manoogian SJ, Bussone WR, Brolinson PG, Goforth MW, et al. (2005) Analysis of real-time head accelerations in collegiate football players. Clin J Sport Med 15: 3-8.

16. Brolinson PG, Manoogian S, McNeely D, Goforth M, Greenwald R et al. (2006) Analysis of linear head accelerations from collegiate football impacts. Curr Sports Med Rep 5: 23-28.

17. Broglio SP, Eckner JT, Surma T, Kutcher JS (2011) Post-concussion cognitive declines and symptomatology are not related to concussion biomechanics in high school football players. J Neurotrauma 28: 2061-2068. 